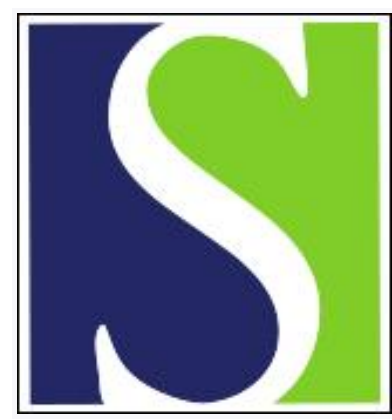

Scand J Work Environ Health 2012;38(6):537-545

https://doi.org/10.5271/sjweh.3286

Published online: 27 Feb 2012, Issue date: 01 Nov 2012

Association between change in employment status and new-onset depressive symptoms in South Korea - a gender analysis

by Kim S-S, Subramanian SV, Sorensen G, Perry MJ, Christiani DC

Affiliation: Department of Environmental and Occupational Health, The George Washington University School of Public Health and Health Services, 2300 Eye Street, NW, Washington, DC 20037, USA. sskim@gwu.edu

The following articles refer to this text: 2014;40(4):343-352;

2014;40(5):465-472; 2015;41(4):329-337; 2017;43(5):457-464; 2021;47(7):509-520

Key terms: depression; depressive symptom; employment status; gender; gender difference; mental health; South Korea

This article in PubMed: www.ncbi.nlm.nih.gov/pubmed/22370923 


\title{
Association between change in employment status and new-onset depressive symptoms in South Korea - a gender analysis
}

\author{
by Seung-Sup Kim, MD, ScD, ${ }^{1}$ SV Subramanian, PhD, ${ }^{2}$ Glorian Sorensen, PhD, ${ }^{2,3}$ Melissa J Perry, ScD, ${ }^{1,4}$ \\ David C Christiani MD ${ }^{4}$
}

\begin{abstract}
Kim S-S, Subramanian SV, Sorensen G, Perry MJ, Christiani DC. Association between change in employment status and new-onset depressive symptoms in South Korea - a gender analysis. Scand J Work Environ Health. 2012;38(6):537-545. doi:10.5271/sjweh.3286
\end{abstract}

\begin{abstract}
Objectives This study aimed to investigate the association of change in employment status with new-onset depressive symptoms, particularly differences stemming from workers' gender, in South Korea.

Methods We analyzed data from the ongoing Korean Welfare Panel Study. After excluding participants who had depressive symptoms at baseline (2007), we analyzed 2891 participants who became a precarious or permanent worker or unemployed at follow-up (2008) among waged workers who were permanent or precarious workers at baseline. Workers were classified as permanent workers if they had full-time, secure jobs and were directly hired by their employers; workers not meeting all these criteria were classified as precarious workers. Depressive symptoms were assessed annually using the 11-item Center for Epidemiologic Studies Depression Scale. To reduce potential bias due to pre-existing health conditions, we also examined the association in a subpopulation excluding participants with any pre-existing chronic disease or disability.
\end{abstract}

Results Compared to those who maintained permanent employment, workers who became unemployed following precarious employment had higher odds of developing depressive symptoms [odds ratio (OR) 2.30, 95\% confidence interval (95\% CI) 1.01-5.25]. In gender-stratified analyses, new-onset depressive symptoms were strongly associated with the change from precarious to permanent employment (OR 2.57, 95\% CI 1.20-5.52) as well as the change from permanent to precarious employment (OR 2.88, 95\% CI 1.24-6.66) among females; no significant association was observed in the male subpopulation.

Conclusions This study found that changes from precarious to permanent work or from permanent to precarious work were associated with new-onset depressive symptoms among South Korean women.

Key terms depression; gender difference; mental health.

The number of workers in precarious employment has been increasing worldwide (1). According to the Organization for Economic Cooperation and Development (OECD) statistics, more than 1.8 billion people - more than half the labor force in developing countries - are currently working without formal contracts and benefits and earning low wages. This number is expected to increase to two-thirds of the workforce in developing countries by 2020 (2). Evidence also demonstrates an increase in precarious employment and a decrease in permanent full-time employment in developed countries in Europe and North America (3-5).

It is well-known that unemployment is an independent risk factor for poor mental health status, including depression (6-7). For example, Brenner and Levi's research using longitudinal data on Swedish women suggests that long-term unemployment could be associated with poor psychological well-being and severe depressive reaction (8). However, much less research has been devoted to determining whether precarious employment

1 Department of Environmental and Occupational Health, George Washington University, School of Public Health and Health Services, Washington, DC, USA.

2 Department of Society, Human Development, and Health, Harvard School of Public Health, Boston, MA, USA.

3 Center for Community Based Research, Dana Faber Cancer Institute, Boston, MA, USA.

4 Department of Environmental Health, Harvard School of Public Health, Boston, MA, USA.

Correspondence to: Seung-Sup Kim, Department of Environmental and Occupational Health, George Washington University School of Public Health and Health Services, 2300 I Street, NW, Washington, DC 20037, USA. [E mail: sskim@gwu.edu] 
is related to mental health outcomes, despite indications that precarious employment involves lower income, job insecurity, lower job autonomy, and poor supervisor support - all potential risk factors for depression (9-11). Several studies in Finland showed that precarious jobs, such as temporary or atypical employment, were associated with depression after adjusting for potential confounders (12-14). Another study, of female workers in South Korea, reported that precarious employment is associated with a higher prevalence of mental disorders compared to permanent employment (15). However, due to their cross-sectional design, these studies could not determine the temporal relationship between precarious employment and depression (12-15). In addition, Virtanen et al (16) showed that poor mental health conditions such as hostility and aggressiveness are predictive of temporary employment, implying a possible reverse causation: people with poor mental health conditions may be more likely to be precarious employees.

Even among prospective studies, the association between precarious employment and depression is controversial. The Whitehall II study (17) in Britain showed that change toward secure permanent employment was inversely associated with depression among male civil servants. Prospective studies in Denmark have shown that job insecurity, a major characteristic of precarious employment, is an independent predictor of depression (18-19). In contrast, Bardasi et al (20) concluded that precarious employment, including temporary and part-time employment, was not related to mental health. Further, very few employment transitions were associated with worsening health outcomes using 10-year longitudinal data with annual follow-up. Importantly, these previous prospective studies were conducted in Western countries, which have different social contexts in terms of labor market policies and welfare states, perhaps making them less applicable to East Asian countries (18-21).

Emerging concerns suggest that women's health could be disproportionately affected by precarious employment (22). Menendez et al (23) pointed out that gender division of labor and patriarchy are more likely to force women to work in precarious employment with lower-paid and shorter-term contract jobs. Additionally, women with precarious jobs tend to experience constant variations in work schedule, producing hardship in balancing work and family responsibilities. However, few studies have examined how the impact of precarious employment on health could differ by gender.

South Korea, which has a relatively weak labor force and underdeveloped welfare programs (24-25), has experienced an increase in the precarious workforce in the last two decades. In 2010, an estimated 39.7\% of male workers and $63.5 \%$ of female workers were precarious employees in South Korea (26). Therefore, we prospectively examined how change in employment status is related to new-onset depressive symptoms and whether this association differs by gender using nationally representative data from South Korea.

\section{Methods}

We analyzed data from the ongoing Korean Welfare Panel Study (hereafter KOWEPS), an annual, nationwide, longitudinal study of a representative sample of 18856 participants from 7072 households who were recruited by two-stage stratified cluster sampling at baseline (www. koweps.re.kr). In conjunction with the Social Welfare Research Institute of Seoul National University, the Korean Institute of Social and Health Affairs launched KOWEPS in 2006. To date, data from the $1^{\text {st }}$ through the $4^{\text {th }}$ waves (2006-2009) have been publicly released. A full description of the study can be found in the most recent version of the KOWEPS user's guide (27).

The classification of employment in the $1^{\text {st }}$ wave survey (conducted in November-December 2006) was different from the $2^{\text {nd }}$ and $3^{\text {rd }}$ wave surveys (conducted in April-July of 2007 and 2008, respectively); the present analyses used participants from the $2^{\text {nd }}$ survey as a baseline study population to maintain consistent classification of employment status over time. At each of the three surveys, the interviewer queried the worker's employment status at December 31 of the prior year.

\section{Measurement of employment status}

Employment status of waged workers was classified as either permanent or precarious. KOWEPS contains a structured set of questions to define precarious employment, accounting for the unique employment situations in South Korea. In this study, only workers who satisfied all four of the following conditions were defined as permanent workers: (i) directly hired by their employers (not subcontracted or dispatched workers or selfemployed workers without employees); (ii) full-time workers (not part-time workers); (iii) no fixed term in their employment contract (not temporary workers); and (iv) a high probability of maintaining the current job (having relatively less job insecurity and not a day laborer). Those who did not meet all four criteria were categorized as precarious workers. Unemployed workers were defined as those who were not employed at the time of the survey and had been actively looking for a job during the previous four weeks. Day laborers and temporary workers who were not working at the time of survey but planned to work were classified as precarious workers.

There were 17478 participants at baseline $\left(2^{\text {nd }}\right.$ wave survey of KOWEPS, 2007). The baseline study 
population was limited to participants who did not have depressive symptoms and who were either permanent workers or precarious workers older than 18 years. After excluding workers with missing values for any variables used in the analyses, a total of 2891 workers were analyzed in this study (figure 1.). We measured the change in employment status by checking employment status at follow-up ( $3^{\text {rd }}$ wave survey, 2008). When employment status was permanent or precarious worker or unemployed at follow-up (2008), they were included in the analyses (hereafter, full population). Therefore, change in employment status was categorized into six groups: (i) maintaining permanent employment (reference group); (ii) changing from permanent to precarious employment; (iii) becoming unemployed from permanent employment; (iv) maintaining precarious employment; (v) changing from precarious to permanent employment; and (vi) becoming unemployed from precarious employment.

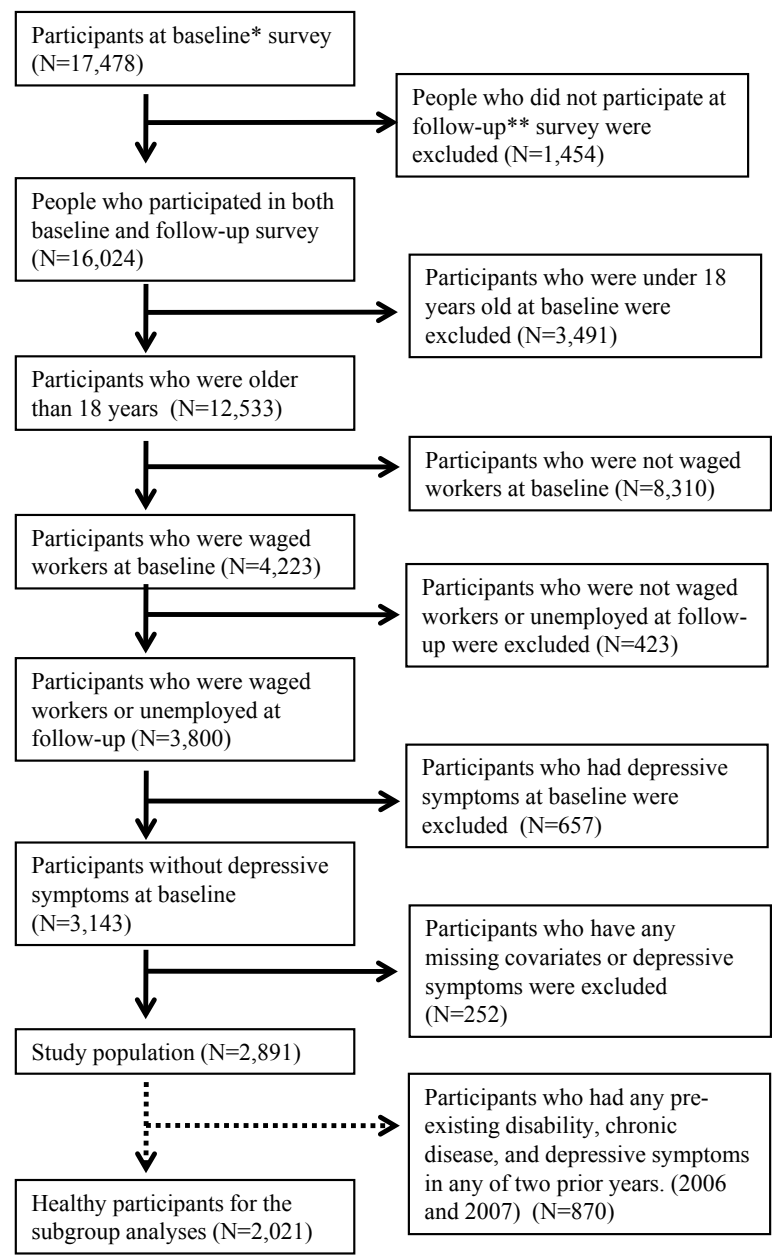

Figure 1. Flow diagram for selection of study population. ${ }^{*} 2^{\text {nd }}$ wave survey (2007) of the Korean Welfare Panel Study. ${ }^{* *} 3^{\text {rd }}$ wave survey (2008) of the Korean Welfare Panel Study

\section{Outcome variables and covariates}

Using the 11-question version of the Centers for Epidemiologic Studies Depression Scale (hereafter, CES-D), KOWEPS assessed depressive symptoms annually (28). The summed score of the 11-question version CES-D ranged from 0-33 and the present study defined conditions with a summed score $>9$ as depressive symptoms (29). Several validation studies have shown that CES-D has a reasonable psychometric property in South Korea and other East-Asian countries (30-33) .

All potential confounders were measured at baseline survey (2007). Age was included as a continuous variable; education was classified as junior high or less, high school, college, and university or more; marital status was divided into currently married, never married, and previously married, including the widowed and divorced; and residential area was assessed as living in a metropolitan area or in a rural area. Equivalized household income, calculated by dividing household income by the square root of the number of household members, was log-transformed and included as a continuous variable.

We also considered health-related confounders disability, chronic disease, and smoking - measured at baseline. They were included as dichotomous variables: having any disability (versus none), having any chronic disease (versus none), and current smoker (versus current non-smoker).

\section{Data analysis}

Multivariate logistic regressions were applied to examine the associations between change in employment status and new-onset depressive symptoms. To examine whether the association differed by gender, we created five interaction terms by multiplying gender and change in employment status. In addition, to reduce potential bias due to pre-existing health conditions, we generated a smaller population (hereafter, subpopulation) after excluding workers who had pre-existing disability, chronic disease, or depressive symptoms in any of the two prior years (2006 and 2007). We checked the significance of five interaction terms as a whole in a fully-adjusted model with the full population as well as the subpopulation. Because depressive symptoms in workers belonging to the same family could be interrelated (598 workers had family members among 2891 workers), we used the Huber-White sandwich estimator to calculate odds ratio (OR) confidence intervals (CI) robust to within-family correlation (34-35). The associations are summarized as estimated OR with their $95 \% \mathrm{CI}$. All analyses were performed using STATA/SE version 11.0 (StataCorp, College Station, TX, USA). 


\section{Results}

Compared to workers who maintained permanent employment, precarious workers were more likely to be women, have less education, be previously married, be smokers, and have chronic diseases (table 1). The overall incidence of depressive symptoms was $9.5 \%$ (274/2891 participants), but tended to be higher for females, people aged $\geq 65$ years, and those with less education. Previously married people were more likely

Table 1. Employment status and incidence of depressive symptoms at follow-up (2008) among workers in South Korea without depressive symptoms at baseline (2007), by sociodemographic characteristics and health-related conditions ( $\mathrm{N}=2891)$. [Perm employ=permanent employment; precar employ=precarious employment.]

\begin{tabular}{|c|c|c|c|c|c|}
\hline \multirow[t]{2}{*}{ Characteristics } & $\begin{array}{c}\text { Perm } \\
\text { employ } \\
(\mathrm{N}=1654)\end{array}$ & $\begin{array}{c}\text { Precar } \\
\text { employ } \\
(\mathrm{N}=1237)\end{array}$ & $\begin{array}{c}\mathrm{P}- \\
\text { value }^{\mathrm{a}}\end{array}$ & \multirow{2}{*}{$\begin{array}{c}\text { New-onset } \\
\text { depressive } \\
\text { symptoms } \\
(\mathrm{N}=2891) \\
\%\end{array}$} & \multirow[t]{2}{*}{$\begin{array}{c}\mathrm{P}- \\
\text { value }^{\mathrm{b}}\end{array}$} \\
\hline & $\%$ & $\%$ & & & \\
\hline \multicolumn{6}{|l|}{ Sociodemographics } \\
\hline Gender & & & $<0.001$ & & 0.034 \\
\hline Male & 66.9 & 57.4 & & 8.6 & \\
\hline Female & 33.1 & 42.6 & & 11.0 & \\
\hline Age (years) & & & $<0.001$ & & 0.003 \\
\hline$\leq 24$ & 3.3 & 2.2 & & 2.6 & \\
\hline $25-34$ & 31.9 & 22.1 & & 7.8 & \\
\hline $35-44$ & 35.2 & 30.0 & & 7.8 & \\
\hline $45-54$ & 20.8 & 22.1 & & 11.5 & \\
\hline $55-64$ & 7.1 & 14.1 & & 13.4 & \\
\hline$\geq 65$ & 1.8 & 9.5 & & 14.2 & \\
\hline Education & & & $<0.001$ & & $<0.001$ \\
\hline Junior high or less & 12.3 & 30.4 & & 16.4 & \\
\hline $\begin{array}{l}\text { High school } \\
\text { graduate }\end{array}$ & 38.1 & 39.0 & & 9.2 & \\
\hline College graduate & 14.5 & 8.6 & & 9.0 & \\
\hline $\begin{array}{l}\text { University grad- } \\
\text { uate or more }\end{array}$ & 35.2 & 22.0 & & 5.4 & \\
\hline \multicolumn{3}{|l|}{ Marital status } & $<0.001$ & & $<0.001$ \\
\hline Currently married & 73.2 & 70.4 & & 8.6 & \\
\hline Never married & 22.2 & 19.0 & & 8.8 & \\
\hline Previously married & 4.6 & 10.7 & & 20.2 & \\
\hline \multicolumn{3}{|l|}{ Residential area } & 0.366 & & 0.068 \\
\hline Rural area & 49.0 & 47.3 & & 8.5 & \\
\hline Metropolitan area & 51.0 & 52.7 & & 10.4 & \\
\hline \multicolumn{6}{|c|}{ Health-related conditions } \\
\hline Smoking & & & 0.002 & & 0.485 \\
\hline Yes & 37.3 & 31.8 & & 10.0 & \\
\hline No & 62.7 & 68.2 & & 9.2 & \\
\hline Having any disability & & & 0.127 & & 0.670 \\
\hline Yes & 2.8 & 3.8 & & 10.8 & \\
\hline No & 97.2 & 96.2 & & 9.4 & \\
\hline $\begin{array}{l}\text { Having any chronic } \\
\text { disease }\end{array}$ & & & $<0.001$ & & 0.002 \\
\hline Yes & 15.1 & 26.0 & & 12.9 & \\
\hline No & 84.9 & 74.0 & & 8.6 & \\
\hline
\end{tabular}

a P-value of the Chi-square test comparing the distribution of precarious and permanent employment in the different groups.

b P-value of the Chi-square test comparing the incidence of depressive symptoms in the different groups. to develop depressive symptoms compared to those never or currently married. Individuals with disabilities and chronic diseases were also more likely to develop depressive symptoms.

Table 2 shows a gender-specific distribution of the study population by change in employment status and new-onset depressive symptoms at follow-up. For males, 49.9\% maintained permanent employment at follow-up, and $7.2 \%$ developed depressive symptoms at follow-up. For females, 39.2\% maintained permanent employment, and $7.1 \%$ developed depressive symptoms at follow-up. The distribution of new-onset depressive symptoms was similar between male and female workers across change in employment status in general; however, female workers had a higher incidence of new-onset depressive symptoms than male workers among those workers who changed from precarious to permanent employment (11.6\% versus $6.8 \%$ ) or became unemployed from precarious employment (26.7\% versus $18.5 \%)$.

\section{Association between change in employment status and} depressive symptoms

After adjusting for confounders, our analyses showed that the odds of depressive symptoms among people who became unemployed from precarious employment were 2.3 times higher (OR 2.69, 95\% CI 1.01-5.85) (table 3). However, no significant association was observed in the subpopulation analyses restricted to workers without any chronic disease or disability at baseline.

Both populations were checked for gender interaction: the P-value for five gender interaction terms as a whole was 0.545 in the full population and $<0.001$ in the subpopulation. Since there was a statistically significant interaction by gender in the subpopulation, we stratified the subpopulation by gender and examined the association between change in employment

Table 2. Change in employment status and new-onset depressive symptoms, stratified by gender $(\mathrm{N}=2891)$.

\begin{tabular}{|c|c|c|c|c|c|c|c|c|}
\hline \multirow{3}{*}{$\begin{array}{l}\text { Employment status } \\
\text { Baseline (2007) } \\
\text { Follow-up (2008) }\end{array}$} & \multicolumn{4}{|c|}{ Male $(\mathrm{N}=1874)$} & \multicolumn{4}{|c|}{ Female $(\mathrm{N}=1077)$} \\
\hline & \multicolumn{2}{|c|}{$\begin{array}{l}\text { Distrib- } \\
\text { ution }\end{array}$} & \multicolumn{2}{|c|}{$\begin{array}{l}\text { Incidence of } \\
\text { depressive } \\
\text { symptoms }\end{array}$} & \multicolumn{2}{|c|}{$\begin{array}{l}\text { Distrib- } \\
\text { ution }\end{array}$} & \multicolumn{2}{|c|}{$\begin{array}{c}\text { Incidence of } \\
\text { depressive } \\
\text { symptoms }\end{array}$} \\
\hline & $\mathrm{N}$ & $\%$ & N & $\%$ & $\mathrm{~N}$ & $\%$ & N & $\%$ \\
\hline \multicolumn{9}{|l|}{ Baseline: permanent } \\
\hline Follo & 906 & 49.9 & 65 & 7.2 & 422 & 39.2 & 30 & 7.1 \\
\hline Follov & 181 & 10 & 16 & 8.8 & 108 & 10.0 & 16 & 14.8 \\
\hline Follow-up & 17 & 0.9 & 2 & 11.8 & 20 & 1.9 & 2 & 10. \\
\hline \multicolumn{9}{|l|}{ Baseline: precarious } \\
\hline Follow-up: precariol & 343 & 18.9 & 45 & 13.1 & 331 & 30.7 & 46 & 13.9 \\
\hline & 340 & 18.7 & 23 & 6.8 & 181 & 16.8 & 21 & 11.6 \\
\hline Follow-up: unemployed & 27 & 1.5 & 5 & 18.5 & 15 & 1.4 & & 26.7 \\
\hline
\end{tabular}


Table 3. Association between change in employment status and new-onset depressive symptoms (2008) in South Korea. [0R=0dds ratio; $95 \% \mathrm{Cl}=95 \%$ confidence interval]

\begin{tabular}{|c|c|c|c|c|c|c|c|c|}
\hline \multirow{3}{*}{$\begin{array}{l}\text { Employment status } \\
\text { Baseline (2007) } \\
\text { Follow-up (2008) }\end{array}$} & \multicolumn{4}{|c|}{ Full population $(\mathrm{N}=2891)$} & \multicolumn{4}{|c|}{ Subpopulation a $(\mathrm{N}=2021)$} \\
\hline & \multicolumn{2}{|c|}{ Unadjusted } & \multicolumn{2}{|c|}{ Fully adjusted ${ }^{b}$} & \multicolumn{2}{|c|}{ Unadjusted } & \multicolumn{2}{|c|}{ Fully adjusted c } \\
\hline & $\mathrm{OR}$ & $95 \% \mathrm{Cl}$ & OR & $95 \% \mathrm{Cl}$ & $\mathrm{OR}$ & $95 \% \mathrm{Cl}$ & OR & $95 \% \mathrm{Cl}$ \\
\hline \multicolumn{9}{|l|}{ Baseline: permanent } \\
\hline Follow-up: permanent & 1.00 & Referent & 1.00 & Referent & 1.00 & Referent & 1.00 & Referent \\
\hline Follow-up: precarious & $1.61^{d}$ & $1.06-2.47$ & 1.25 & $0.81-1.94$ & $2.06^{e}$ & $1.21-3.48$ & 1.66 & $0.97-2.84$ \\
\hline Follow-up: unemployed & 1.57 & $0.55-4.53$ & 1.27 & $0.45-3.65$ & 0.71 & $0.09-5.30$ & 0.57 & $0.80-4.05$ \\
\hline \multicolumn{9}{|l|}{ Baseline: precarious } \\
\hline Follow-up: precarious & $2.03^{f}$ & $1.50-2.74$ & 1.22 & $0.88-1.68$ & $2.09^{f}$ & $1.38-3.15$ & 1.44 & $0.94-2.23$ \\
\hline Follow-up: permanent & 1.20 & $0.83-1.73$ & 1.00 & $0.68-1.46$ & 1.40 & $0.87-2.25$ & 1.22 & $0.75-1.96$ \\
\hline Follow-up: unemployed & 3.54 e & $1.65-7.60$ & $2.30^{d}$ & $1.01-5.25$ & $3.98^{d}$ & $1.30-12.18$ & 2.67 & $0.84-8.40$ \\
\hline $\begin{array}{l}\text { The population includes } \\
\text { 2007). } \\
\text { b Adjusted for age, sex, m } \\
\text { having any disability at } \\
{ }^{c} \text { Adjusted for age, sex, m } \\
\text { d } P<0.05 \text {. } \\
\text { e } P<0.01 \text {. }\end{array}$ & $\begin{array}{l}\text { lout a dis } \\
\text { educatio } \\
\text { educatio }\end{array}$ & $\begin{array}{l}\text { ity or chronic } \\
\text { level, househ } \\
\text { level, househ }\end{array}$ & quivalize at b & $\begin{array}{l}\text { ine and with } \\
\text { come, reside } \\
\text { come, reside }\end{array}$ & $\begin{array}{l}\text { lepressiv } \\
\text { I area, sn } \\
\text { I area, an }\end{array}$ & $\begin{array}{l}\text { ymptoms in th } \\
\text { ing status, ha } \\
\text { moking status }\end{array}$ & $\begin{array}{l}\text { o prior } \\
\text { any chr } \\
\text { aseline }\end{array}$ & $\begin{array}{l}\text { (2006 and } \\
\text { disease, and }\end{array}$ \\
\hline
\end{tabular}

Table 4. Gender-specific association between change in employment status and new-onset depressive symptoms (2008) in South Korea. [OR=odds ratio; $95 \% \mathrm{Cl}=95 \%$ confidence interval]

\begin{tabular}{|c|c|c|c|c|c|c|}
\hline \multirow{3}{*}{$\begin{array}{l}\text { Employment status } \\
\text { Baseline (2007) } \\
\text { Follow-up (2008) }\end{array}$} & \multicolumn{6}{|c|}{ Fully adjusted model in the subpopulation a, b } \\
\hline & \multicolumn{3}{|c|}{ Male $(\mathrm{N}=1296)$} & \multicolumn{3}{|c|}{ Female $(\mathrm{N}=725)$} \\
\hline & $\mathrm{N}$ & R & li & $\bar{N}$ & OR & $95 \% \mathrm{Cl}$ \\
\hline \multicolumn{7}{|l|}{ Baseline: permanent } \\
\hline Follow-un $n$ & 709 & 00 & ent & 329 & 1.00 & Referer \\
\hline Follov & 121 & 1.19 & $0.5 \%$ & 13 & & \\
\hline Follon & d 10 & 1.54 & & & & \\
\hline \multicolumn{7}{|l|}{ Baseline: precarious } \\
\hline & 192 & & & 182 & 1.50 & \\
\hline & 253 & 0.76 & & 115 & 2.5 & \\
\hline Follow-up: unemployed & d 11 & 0.84 & $0.10-7.00$ & 10 & & 32.2 \\
\hline \multicolumn{7}{|c|}{$\begin{array}{l}\text { a Adjusted for age, sex, marital status, educational level, household } \\
\text { equivalized income, residential area, and smoking status at baseline. } \\
\text { b The population includes workers without a disability or chronic disease } \\
\text { at baseline and without depressive symptoms in the two prior years } \\
\text { ( } 2006 \text { and 2007). } \\
\text { c } P<0.05 \text {. } \\
\text { d Female workers who became unemployed from permanent employment } \\
\text { were excluded in the analysis because none of them developed depres- } \\
\text { sive symptoms at the follow-up. }\end{array}$} \\
\hline
\end{tabular}

status and new-onset depressive symptoms separately for male and female workers (table 4). No statistically significant association was observed in the male subpopulation. However, in the female subpopulation, changes from permanent to precarious employment (OR $2.88,95 \%$ CI 1.24-6.66) and from precarious employment to unemployed (OR 8.01, 95\% CI 1.99-32.26) were significantly associated with new-onset depressive symptoms. Further, the change from precarious to permanent employment was also significantly associated with new-onset depressive symptoms (OR 2.57, 95\% CI $1.20-5.52)$ in the female subpopulation.

\section{Discussion}

Our results indicate that changes from precarious to permanent work or from permanent to precarious work were associated with new-onset depressive symptoms among South Korean women. Workers who became unemployed following precarious employment had higher odds of developing new-onset depressive symptoms compared to those who maintained permanent employment, after adjusting for confounders. Additionally, the association between change in employment status and new-onset depressive symptoms was affected by workers' gender in the subpopulation analyses restricted to workers without any chronic disease or disability at baseline and without depressive symptoms in the two prior years (2006 and 2007).

The gender stratification revealed a significant difference in the association between change in employment status and new-onset depressive symptoms. Notably, new-onset depressive symptoms were strongly associated with a change from precarious to permanent employment as well as from permanent to precarious employment for female workers. However, no significant association was observed for male workers. It is also noteworthy that in a subpopulation of healthy male workers, those who became unemployed from precarious employment were not at greater risk of new-onset depressive symptoms. 
This phenomenon suggests a possibility that baseline physical illness may be the reason for developing depressive symptoms for male workers who became unemployed following precarious employment. The potential role of baseline physical illness in unemployment could also be investigated; it is possible that unhealthy workers were laid off due to their physical conditions, while healthy workers were laid off for financial or other reasons not connected to their health.

Interestingly, we also detected a strong association with depressive symptoms for female workers changing from precarious to permanent employment. This perhaps indicates that a shift toward secure, fulltime employment may put female workers at risk for depressive symptoms. The finding is consistent with a previous Korean study describing that female workers who moved from precarious to permanent employment reported poorer health compared to female workers who maintained permanent employment (36). At least three explanations can be proposed. First, women may have more difficulty maintaining work/life balance when holding a full-time job than part-time precarious employment because they retain considerable domestic responsibilities. This is particularly plausible in South Korea, where, because of strong patriarchal social traditions (24) and the Confucian ideology of male superiority (37), females are required to undertake most domestic responsibility regardless of their employment. A second possible explanation is that the permanent jobs available to female precarious workers, though more secure, may not be better in terms of wages or working conditions. Previous research found pervasive workrelated discrimination (eg, discrimination in hiring, pay, and promotion) for female workers in South Korea (38). Finally, it is possible that female workers moving from part- to full-time work are making the shift due to a partner's illness or disability that prevents full-time work. Since previous studies found that family caregivers are at high risk of developing depressive symptoms (39), female workers who increase their work hours to support an ill or disabled partner are likely at high risk of developing depressive symptoms. Future studies are required to investigate the exact mechanisms by which employment change produces poor health outcomes among female workers, with more consideration that women's health could be disproportionately affected by the labor market and workplace flexibility (23).

In the analyses with the full population, an interesting difference was noted in the relationship between becoming unemployed and new-onset depressive symptoms based on workers' previous employment status. When precarious workers became unemployed, the odds of developing depressive symptoms were significantly higher than for those who remained permanently employed. However, permanent workers who lost their jobs were not at a higher risk for depressive symptoms. Previous studies in South Korea have shown that precarious workers are more likely to have poor mental health than permanent workers $(15,40)$. Additionally, unemployment is an important risk factor for depressive symptoms $(7,41-42)$. Therefore, the change from precarious employment to unemployment could be a "double burden" to mental health.

An alternative explanation for this phenomenon is social, financial, and contextual issues that are often involved when a worker becomes unemployed. For example, permanent employment is more likely to be seen as "official employment" compared to precarious employment in the context of receiving severance pay. In South Korea in 2010, 27.3\% of precarious workers were eligible for severance pay compared to $99.3 \%$ of permanent workers (26). Additionally, the change from permanent employment to unemployment could be voluntary: permanent workers were defined as those with good job stability, making them less likely to be forced to leave a position. Thus, in terms of financial status and social support, permanent workers may be better equipped to deal with unemployment than precarious workers. Notably, however, our study may prohibit a valid inference because of the small number of participants who transitioned to unemployed from permanent employment $(\mathrm{N}=41)$.

Finally, a biological pathway could be considered because both unemployment and precarious employment might affect human immune functions (43). Arentz et al (44) reported that unemployment may aggravate some aspects of the immune system such as phytohemagglutinin reactivity of lymphocytes. Job insecurity, which is common in precarious employment, is also known to be associated with an increased risk of flu-like illness even after adjusting for confounders such as the presence of a longstanding illness (45). More biological research is required to understand how becoming unemployed from precarious employment is linked to depressive symptoms.

The present analyses have several limitations. First, there could be issues in classifying precarious employment due to the dichotomous classification. But since this potential misclassification was not associated with new-onset depressive symptoms, we expect any misclassification to be non-differential, which might bias the result toward the null. Another issue is that the definition of precarious employment in this paper includes the female workers who voluntarily decided to work part-time because their partner is the main breadwinner, and those workers may not be at a higher risk of feeling job insecurity or depression. Future research could use a more specific classification or a continuous scale such as "precariousness", which can capture differences within each of the categories of permanent and precarious employment (10, 46-47). 
Second, there may be potential selection bias. Participants who developed depressive symptoms were less likely to participate in the follow-up survey, and these individuals were more likely to be precarious workers or unemployed. However, $92 \%$ of the baseline study population completed the survey at follow-up, thus the influence of selection bias on the association is expected to be relatively small.

Third, despite adjusting for potential confounders, including health-related conditions, unmeasured residual confounders may exist. We did not have any information about participants' medical history of depressive symptoms or other mental disorders. However, our analyses adjusted for baseline health conditions (ie, having any chronic diseases or any disability), which are strongly related to depressive symptoms $(48,49)$, and we also found a consistent relationship in the subpopulation analyses after excluding participants with depressive symptoms during the two prior years. So the bias caused by these unmeasured confounders would not fully explain the strong association we found.

The present study has several strengths. First, we obtained a large study population that is nationally representative of South Korea. Second, compared to previous cross-sectional studies in South Korea $(15,40)$, the present study's prospective design, which excluded participants with depressive symptoms at baseline, makes it robust against the possibility that people with depressive symptoms are more likely to become precarious workers. Third, we found significant relationships between change in employment status and new-onset depressive symptoms after adjusting for potential confounders and excluding participants with other health conditions that could be a source of new-onset depressive symptoms. Fourth, permanent and precarious employment was assessed using a structured questionnaire that considered the unique employment relationships in South Korea. Compared to previous research that defined precarious employment as workers with part-time, daily labor, and temporary employment (40), the definition of precarious employment in the present research included other types of vulnerable employment, such as subcontract workers, dispatched workers, etc. Finally, most previous studies focused on the health effects of transition from precarious to permanent employment (50-52), but the present analyses also explored the health effect of changing from permanent to precarious employment.

\section{Concluding remarks}

This study found that becoming unemployed is associated with new-onset depressive symptoms when previous employment status was precarious. Additionally, we reported a specific impact on female workers, showing that changes from precarious to permanent employment and from permanent to precarious employment were associated with new-onset depressive symptoms only among females. To our knowledge, this is one of the first prospective studies to show that the association between change in employment status and depressive symptoms differs by workers' gender.

\section{Acknowledgements}

The authors' declare no financial or other relationships that may lead to conflicts as regards the publication of this material. There was no financial support for this research.

\section{References}

1. International Labour Office. Global employment trends. Geneva. International Labour Office; 2010.

2. Jütting J, Laiglesia JRd, editors. Is Informal Normal? Towards More and Better Jobs in Developing Countries: Organisation for Economic Cooperation and Development 2009.

3. DeGrip A, Hoevenberg J, Willems E. Atypical employment in the European Union. International Labour Review. 1997 Spr;136(1):49-71.

4. Bureau of Labor Statistics. Contingent and Alternative Employment. US Department of Labor. Washington, DC; 2005.

5. Bielenski H. New patterns of employment in Europe. WHO Reg Publ Eur Ser. 1999;81:11-30.

6. Frese M, Mohr G. Prolonged unemployment and depression in older workers: a longitudinal study of intervening variables. Soc Sci Med. 1987;25(2):173-8. http://dx.doi. org/10.1016/0277-9536(87)90385-6.

7. Mossakowski KN. The influence of past unemployment duration on symptoms of depression among young women and men in the United States. Am J Public Health. 2009;Oct;99(10):1826-32. http://dx.doi.org/10.2105/ AJPH.2008.152561.

8. Brenner S-O, Levi L. Long-term unemployment among women in Sweden. Soc Sci Med. 1987;25(2):153-61. http://dx.doi.org/10.1016/0277-9536(87)90383-2.

9. Quinlan M, Mayhew C, Bohle P. The global expansion of precarious employment, work disorganization, and consequences for occupational health: a review of recent research. Int J Health Serv. 2001;31(2):335-414. http://dx.doi. org/10.2190/607H-TTV0-QCN6-YLT4.

10. Vives A, Amable M, Ferrer M, Moncada S, Llorens C, Muntaner C, et al. The Employment Precariousness Scale (EPRES): psychometric properties of a new tool for epidemiological studies among waged and salaried workers. Occup Environ Med. 2010 Aug;67(8):548-55. http://dx.doi. org/10.1136/oem.2009.048967. 
11. Bonde JPE. Psychosocial factors at work and risk of depression: a systematic review of the epidemiological evidence. Occup Environ Med. 2008;65(7):438-45.

12. Virtanen M, Kivimaki M, Ferrie JE, Elovainio M, Honkonen T, Pentti J, et al. Temporary employment and antidepressant medication: a register linkage study. J Psychiatr Res. 2008;42(3):221-9. http://dx.doi.org/10.1016/j. jpsychires.2006.12.005.

13. Virtanen P, Liukkonen V, Vahtera J, Kivimaki M, Koskenvuo M. Health inequalities in the workforce: the labour market core-periphery structure. Int J Epidemiol. 2003;32(6):1015-21. http://dx.doi.org/10.1093/ije/dyg319.

14. Virtanen P, Vahtera J, Kivimaki M, Pentti J, Ferrie J. Employment security and health. J Epidemiol Commun H. 2002;56(8):569-74. http://dx.doi.org/10.1136/jech.56.8.569.

15. Kim IH, Khang YH, Muntaner C, Chun H, Cho SI. Gender, precarious work, and chronic diseases in South Korea. Am J Ind Med. 2008;51(10):748-57. http://dx.doi.org/10.1002/ ajim.20626.

16. Virtanen M, Kivimäki M, Elovainio M, Vahtera J, Kokko $\mathrm{K}$, Pulkkinen L. Mental health and hostility as predictors of temporary employment: Evidence from two prospective studies. Soc Sci Med. 2005;61(10):2084-95. http://dx.doi. org/10.1016/j.socscimed.2005.04.028

17. Ferrie JE, Shipley MJ, Stansfeld SA, Marmot MG. Effects of chronic job insecurity and change in job security on self reported health, minor psychiatric morbidity, physiological measures, and health related behaviours in British civil servants: the Whitehall II study. J Epidemiol Commun H. 2002;56(6):450-4. http://dx.doi.org/10.1136/jech.56.6.450.

18. Rugulies R, Bültmann U, Aust B, Burr H. Psychosocial Work Environment and Incidence of Severe Depressive Symptoms: Prospective Findings from a 5-Year Follow-up of the Danish Work Environment Cohort Study. Am J Epidemiol. 2006;163(10):877-87.

19. Rugulies R, Thielen K, Nygaard E, Diderichsen F. Job insecurity and the use of antidepressant medication among Danish employees with and without a history of prolonged unemployment: a 3.5-year follow-up study. J Epidemiol Commun H. 2010;64(01):75-81.

20. Bardasi E, Francesconi M. The impact of atypical employment on individual wellbeing: evidence from a panel of British workers. Soc Sci Med. 2004;58(9):1671-88. http://dx.doi. org/10.1016/S0277-9536(03)00400-3.

21. Dooley D, Prause J, Ham-Rowbottom KA. Underemployment and depression: longitudinal relationships. J Health Soc Behav. 2000;41(4):421-36. http://dx.doi.org/10.2307/2676295.

22. Messing K, Punnett L, Bond M, Alexanderson K, Pyle J, Zahm S, et al. Be the fairest of them all: challenges and recommendations for the treatment of gender in occupational health research. Am J Ind Med. 2003;43(6):618-29. http:// dx.doi.org/10.1002/ajim.10225.

23. Menendez M, Benach J, Muntaner C, Amable M, O'Campo P. Is precarious employment more damaging to women's health than men's? Soc Sci Med. 2007;64(4):776-81.
24. Kim MH, Kim HJ. An untold story in labor health: Korean women workers. New Solut. 2007;17(4):325-43. http://dx.doi.org/10.2190/NS.17.4.h.

25. Kim MH, Kim CY, Park JK, Kawachi I. Is precarious employment damaging to self-rated health? Results of propensity score matching methods, using longitudinal data in South Korea. Soc Sci Med. 2008;67(12):1982-94. http:// dx.doi.org/10.1016/j.socscimed.2008.09.051.

26. Kim Y. The magnitude and reality of precarious employment in South Korea. Seoul: Korean Labour \& Society Institute; 2010.

27. Korean Institute of Social and Health Affairs, Social Welfare Research Institute of Seoul National University. Users' guide : Korea Welfare Panel Study. Seoul: Korean Institute of Social and Health Affairs, Social Welfare Research Institute of Seoul National University; 2010.

28. Radloff LS. The CES-D Scale, A Self-Report Depression Scale for Research in the General Population. Appl Psych Meas. 1977;1(3):385-401. http://dx.doi. org/10.1177/014662167700100306.

29. Takeshita J, Masaki K, Ahmed I, Foley DJ, Li YQ, Chen R, et al. Are depressive symptoms a risk factor for mortality in elderly Japanese American men?: the Honolulu-Asia Aging Study. Am J Psychiatry. 2002;159(7):1127-32. http://dx.doi. org/10.1176/appi.ajp.159.7.1127.

30. Boey KW. Cross-validation of a short form of the CES-D in Chinese elderly. Int $\mathrm{J}$ Geriatr Psychiatry. 1999;14(8):608-17. http://dx.doi.org/10.1002/(SICI)10991166(199908)14:8<608::AID-GPS991>3.0.CO;2-Z.

31. Cheung CK, Bagley C. Validating an American scale in Hong Kong: the Center for Epidemiological Studies Depression Scale (CES-D). J Psychol. 1998;132(2):169-86. http://dx.doi. org/10.1080/00223989809599157.

32. Mackinnon A, McCallum J, Andrews G, Anderson I. The Center for Epidemiological Studies Depression Scale in older community samples in Indonesia, North Korea, Myanmar, Sri Lanka, and Thailand. J Gerontol B Psychol Sci Soc Sci. 1998;53(6):P343-52. http://dx.doi.org/10.1093/ geronb/53B.6.P343.

33. Cho MJ, Kim KH. Use of the Center for Epidemiologic Studies Depression (CES-D) Scale in Korea. J Nerv Ment Dis. 1998;186(5):304-10. http://dx.doi.org/10.1097/00005053199805000-00007.

34. Rogers WH. Regression standard errors in clustered samples. Stata Technical Bulletin. 1993(13):19-23.

35. Williams RL. A note on robust variance estimation for clustercorrelated data. Biometrics. 2000;56(2):645-6. http://dx.doi. org/10.1111/j.0006-341X.2000.00645.x.

36. JinWook Bahk, Yoon Jung Han, Seung Sup Kim. Health Inequity among Waged Workers by Employment Status. J Prev Med Public Health. 2007;40(5):388-96.

37. Soh C-HS. Sexual equality, male superiority, and Korean women in politics: Changing gender relations in a "patriarchal democracy". Sex Roles. 1993;28(1):73-90. http://dx.doi. org/10.1007/BF00289748.

38. Kim S-S, Williams DR. Perceived Discrimination and Self- 
Rated Health in South Korea: A Nationally Representative Survey. PLoS One. 2012;7(1):e30501. http://dx.doi. org/10.1371/journal.pone.0030501].

39. Grunfeld E, Coyle D, Whelan T, Clinch J, Reyno L, Earle CC, et al. Family caregiver burden: results of a longitudinal study of breast cancer patients and their principal caregivers. Can Med Assoc J. 2004;170(12):1795-801.

40. Kim IH, Muntaner C, Khang YH, Paek D, Cho SI. The relationship between nonstandard working and mental health in a representative sample of the South Korean population. Soc Sci Med. 2006;63(3):566-74. http://dx.doi.org/10.1016/j. socscimed.2006.02.004.

41. Linn MW, Sandifer R, Stein S. Effects of unemployment on mental and physical health. Am J Public Health. 1985;75(5):502-6. http://dx.doi.org/10.2105/AJPH.75.5.502.

42. Morrell S, Taylor R, Quine S, Kerr C, Western J. A cohort study of unemployment as a cause of psychological disturbance in Australian youth. Soc Sci Med. 1994;38(11):1553-64. http:// dx.doi.org/10.1016/0277-9536(94)90117-1.

43. Cohen S, Frank E, Doyle WJ, Skoner DP, Rabin BS, Gwaltney JM. Types of stressors that increase susceptibility to the common cold in healthy adults. Health Psychol. 1998;17(3):214-23. http://dx.doi.org/10.1037/0278-6133.17.3.214.

44. Arnetz BB, Wasserman J, Petrini B, Brenner SO, Levi L, Eneroth $\mathrm{P}$, et al. Immune function in unemployed women. Psychosom Med. 1987;49(1):3-12.

45. Mohren DCL, Swaen GMH, van Amelsvoort LGPM, Borm PJA, Galama JMD. Job insecurity as a risk factor for common infections and health complaints. J OccupEnviron Med. 2003;45(2):123-9. http://dx.doi.org/10.1097/01 jom.0000052954.59271.2f.
46. Dooley D. Unemployment, underemployment, and mental health: conceptualizing employment status as a continuum. Am J Community Psychol. 2003;32(1-2):9-20. http://dx.doi. org/10.1023/A:1025634504740.

47. Benach J, Muntaner C, Santana V (Chairs). Employment Conditions Knowledge Network (EMCONET). Employment Conditions and Health Inequalities. Final report to the WHO Commission on Social Determinants of Health (CSDH). 2007.

48. Broadhead WE, Blazer DG, George LK, Tse CK (1990) Depression, Disability Days, and Days Lost From Work in a Prospective Epidemiologic Survey. JAMA 264: 2524-8. http:// dx.doi.org/10.1001/jama.1990.03450190056028.

49. Moussavi S, Chatterji S, Verdes E, Tandon A, Patel V, et al. (2007) Depression, chronic diseases, and decrements in health: results from the World Health Surveys. The Lancet. 370: 8518. http://dx.doi.org/10.1016/S0140-6736(07)61415-9.

50. Virtanen M, Kivimaki M, Elovainio M, Vahtera J. Selection from fixed term to permanent employment: prospective study on health, job satisfaction, and behavioural risks. J Epidemiol Commun H. 2002;56(9):693-9. http://dx.doi.org/10.1136/ jech.56.9.693.

51. Virtanen M, Kivimaki M, Elovainio M, Vahtera J, Ferrie JE. From insecure to secure employment: changes in work, health, health related behaviours, and sickness absence. Occup Environ Med. 2003;60(12):948-53. http://dx.doi.org/10.1136/ oem.60.12.948.

52. Reine I, Novo M, Hammarstrom A. Does transition from an unstable labour market position to permanent employment protect mental health? Results from a 14-year follow-up of school-leavers. BMC Public Health. 2008;8(1):159. http://dx.doi.org/10.1186/1471-2458-8-159.

Received for publication: 7 December 2012 